\title{
The Relative Role of Perceived Partner Risks in Promoting Condom Use in a Three-City Sample of High-Risk, Low-Income Women
}

\author{
Allison J. Ober • Martin Y. Iguchi · Robert E. Weiss • \\ Pamina M. Gorbach • Robert Heimer - Lawrence J. Ouellet • \\ Steven Shoptaw $\cdot$ M. Douglas Anglin $\cdot$ William A. Zule
}

Published online: 26 October 2010

(C) The Author(s) 2010. This article is published with open access at Springerlink.com

\begin{abstract}
We examined the effect of women's perceptions of sexual partner risks on condom use. Women from three US cities $(n=1,967)$ were recruited to provide data on HIV risks. In univariate models, increased odds of condom use were associated with perceiving that partners had concurrent partners and being unaware of partners': (a) HIV status, (b) bisexuality, (c) concurrency; and/or (d) injection drug use. In multivariate models, neither being unaware of the four partner risk factors nor perceiving a partner as being high risk was associated with condom use. Contextual factors associated with decreased odds of condom use were having sex with a main partner, homelessness in the past year, alcohol use during sex, and crack use in the past 30 days. Awareness of a partner's risks may not be sufficient for increasing condom use. Contextual factors,
\end{abstract}

\author{
A. J. Ober $(\varangle) \cdot$ M. D. Anglin \\ Integrated Substance Abuse Programs, David Geffen School \\ of Medicine, Semel Institute for Neuroscience and Behavior, \\ University of California, Los Angeles, 1640 S. Sepulveda \\ Boulevard, Los Angeles, CA 90025, USA \\ e-mail: ajober@ucla.edu \\ M. Y. Iguchi \\ RAND Corporation, Santa Monica, CA, USA \\ M. Y. Iguchi \\ Community Health Sciences Department, \\ School of Public Health, University of California, \\ Los Angeles, Los Angeles, CA, USA \\ R. E. Weiss \\ Biostatistics Department, School of Public Health, University \\ of California, Los Angeles, Los Angeles, CA, USA \\ P. M. Gorbach \\ Department of Epidemiology, School of Public Health, \\ University of California, Los Angeles, Los Angeles, CA, USA
}

sex with a main partner in particular, decrease condom use despite awareness of partner risk factors.

Keywords Perceptions of partner HIV risk behaviors . Condom use · HIV transmission to women · Crack · Alcohol

\section{Introduction}

As the human immunodeficiency virus (HIV) epidemic in the United States continues into its fourth decade, women have become increasingly affected by the disease [1] and unprotected heterosexual sex has long surpassed injection drug use as the leading route of transmission to women [2].

\author{
R. Heimer \\ Yale University School of Public Health, New Haven, \\ Connecticut, USA \\ L. J. Ouellet \\ School of Public Health, University of Illinois, \\ Chicago, USA \\ S. Shoptaw \\ Department of Family Medicine, David Geffen School \\ of Medicine, University of California, Los Angeles, \\ Los Angeles, CA, USA \\ W. A. Zule \\ Research Triangle Institute International, \\ Raleigh-Durham, North Carolina, USA
}


Surveillance data for 2005 indicate that women now represent one quarter of all new cases of HIV [3]; African American women are disproportionately affected, constituting $67 \%$ of reported cases [3]. Due to the late development of HIV testing and identification and the lack of early and adequate interventions, acquired immunodeficiency syndrome (AIDS), the group of conditions caused by HIV as the immune system fails, is the leading cause of death among African American women aged 25-34 and the fifth leading cause of death among African American women aged 35-44 [1]. The increased transmission of HIV to women through heterosexual contact raises questions about the male partners who are the source of their infection. Despite high levels of public understanding of the risk factors and behaviors related to the transmission of HIV, levels of condom use remain unaccountably low $[4,5]$, suggesting that there are gaps in our understanding of the relationship between individual knowledge and behavioral response.

Given these epidemiological data, it is likely that many women may be unaware of or wrong in their assessments about their partners' risk factors [6-8] and/or they may be engaging in unprotected sex despite knowledge of partner risk factors $[9,10]$. Research indicates that women are more likely to contract HIV from main partners or partners considered to be "close" due to the greater likelihood of having unprotected sex with them compared with casual partners or sex trade partners [5, 11]. Women may perceive main or close partners as being "safe" (i.e., monogamous or HIV negative) $[5,12]$, albeit possibly incorrectly [7, 8, 13], or they may perceive them as potentially risky but they have other, competing priorities such as perceived partner disapproval of condom use [14], fear of violence [10] and loss of financial support [15] due to requesting that a partner use a condom, or placing love for their partner over concerns about their own health [9]. Despite well-established evidence that the risk of HIV transmission to women is greatest with main or close partners and a few studies indicating risky sexual behaviors among HIV serodiscordant couples [16, 17], the relative role of perceptions of partner risk factors and behaviors, given contextual factors such as partner type and substance use, remains largely unexamined.

Men's primary risk factors that contribute to HIV transmission to women include: positive HIV status-the high prevalence of HIV among African American men in particular [3, 18]-having concurrent (i.e. overlapping) partners [19], behavioral bisexuality [20], and injection drug use. While some literature suggests that women may be either unaware of or incorrectly perceive their partners' specific risk factors for HIV infection [2, 7, 8, 21], little is known about the extent to which women are aware of their partners' risk factors, the effect of women's perceptions of partner risk factors on condom use, or the moderating effects of contextual factors on the relationship between perceptions of partner risk and condom use (or the reverse-the moderating effects of perceived partner risk on the relationship between contextual factors and condom use).

The influence of risk perceptions on condom use and other protective health prevention behaviors is well-documented through risk perception models such as the health belief model and the theory of reasoned action [22, 23], but such models often do not simultaneously include perceptions of partner risks or important situational and contextual factors that may uniquely influence the protective behaviors of the economically disadvantaged women who are most at risk for HIV [24]. Such analytic deficiencies may explain why models examining the role of perceived risk in HIV risk behaviors have had mixed results and may be limited in their applicability [24]. Several scholars have noted that the application of a single theory of health behavior decision-making and behavior change cannot possibly address all of the factors influencing condom use, particularly among economically disadvantaged women [10, 24-26]. Some of the contextual factors that affect condom use are homelessness [25, 27-30], a woman's knowledge of her own HIV status [31, 32], casual versus chronic substance use [33-39], and sex with a main or close partner compared with another type of partner, such as an unknown partner or a partner with whom sex is exchanged for drugs or money $[5,11,14]$. There is a need for theoretical models that "take more seriously the social contexts in which decisions about health behaviors are made and the constraints that individuals face in making their choices" [24].

In addition to adding contextual factors to risk perception models, some suggest that data on sexual behaviors would be more precise if measured at the event or episode level, within the context of specific sexual episodes, to account for factors that may vary by episode [40-42] and to assist with recall of such practices through appropriate interview methodologies [43]. Risk behaviors are not likely perceived as the same for each person [24] or for each sexual relationship. Using appropriate statistical methodologies to examine behaviors within the context of specific episodes that take partner type, among other factors, into account may be particularly important for women because they typically demonstrate riskier behaviors with main or close partners than with other kinds of partners [5, 14, 44] and often tend to make critical decisions about their own well-being within the context of close relationships with others [45].

This article examines the influence of women's perceptions of four partner risk factors-HIV status, bisexual behavior, sexual partner concurrency (i.e., their having 
other partners that overlap in time), and injection drug use-on condom use at the event-level, taking into account type of partner, homelessness, the woman's HIV status, and drug and alcohol use by the woman and by her partner. Exploring the relationship between a woman's perceptions of partner behaviors and condom use within specific sexual episodes may help illuminate whether awareness of partner risk factors is protective against HIV through increased condom use and whether consideration of such contextual factors affects the relationship between risk perceptions and condom use. Such illumination would, in turn, assist in the design or adaptation of HIV prevention strategies to optimize their impact.

Based on the basic elements of the health belief model, which suggests that awareness of one's own risk for and susceptibility to disease are associated with protective behaviors [46], we hypothesized that women's perceptions that a male partner was HIV positive, had concurrent partners, was also having sex with men, and had a history of injection drug use would be associated in univariate models (i.e., models with a single predictor variable) with increased odds of condom use, before contextual factors were taken into account. We also hypothesized that sex with a main partner, homelessness, and the woman's and man's drug and alcohol use would be associated with decreased odds of condom use and that the woman's positive HIV status would be associated with increased odds of condom use, and that we would see interaction effects between partner risk perceptions and these contextual variables.

As noted, some studies have examined associations between perceived risk and protective behaviors, but few have examined associations between perceptions of risk of specific sexual partners during specific sexual episodes. Event-level, partner-specific data allow for the examination of these relationships.

\section{Methods}

Sample

Respondents were women $(n=1,967)$ from the three US sites (Los Angeles, Chicago, and Raleigh-Durham) that took part in the National Institute on Drug Abuse (NIDA) Sexual Acquisition and Transmission of HIV Cooperative Agreement Program (SATHCAP) between 2005 and 2008. These women were drawn from the full sample ( $n=8,355)$ of male and female respondents from the two waves of the larger study. The primary goal of SATHCAP was to examine the role of substance use and related behaviors in accelerating the sexual diffusion of HIV from high-risk individuals (men who have sex with men [MSM], and drug users [DU]) to the general heterosexual population. Using a respondent-driven sampling (RDS) methodology, men and women in the full sample were recruited because they were either MSM, DU, or sex partners of MSM or DU. RDS is a peer-driven, chain-referral sampling approach that can efficiently yield large samples of difficult-to-access populations such as MSM and DU [47-53].

The women selected had to be eligible as DU, i.e., they reported using (by injection or not) heroin, crack, powder cocaine, or methamphetamine in the past 6 months or they injected some other drug, or as sex partners of an MSM or DU already recruited. The two study waves were almost identical in methodology, but wave 2 incorporated small recruitment changes in order to obtain a greater number of sexual partners of higher-risk individuals.

\section{Procedures}

Study procedures and consent forms at all sites were approved by each institution's Institutional Review Board. SATHCAP investigators conducted a two-wave, crosssectional study across all sites using RDS to recruit DU and MSM [54]. All sites began recruitment in each SATHCAP wave with the selection of "seeds," i.e., outgoing, highly social members of a social network of either MSMs or male or female DUs who were willing to participate and to also recruit individuals they knew (Fig. 1). Seeds had to meet the study's eligibility requirements, as follows: (1) MSM: a male who reported having sex with another man in the past 6 months; and/or (2) DU: a male or female who reported using crack cocaine, powder cocaine, or heroin, or injecting some other drug in the past 6 months. In the first wave, seeds were given three coupons after participating in the study interview and testing for HIV and other sexually transmitted infections to recruit other primary risk group members (male or female DU or MSM) and three coupons to recruit their male or female sex partners. In the second wave, recruitment criteria changed to increase recruitment of non drug-using sexual partners of these high-risk participants. In wave 2, seeds initially were given two coupons to recruit other primary risk group members and two coupons to recruit a sexual partner of the opposite sex. All sites eventually increased the number of primary risk group coupons to four in order to increase recruitment rates. Respondents had to present authenticated coupons and meet the study's eligibility requirements. Respondents who completed the study also were eligible to become recruiters if they were willing. Eligible respondents completed the study's audio, computerized, self-administered interview (ACASI), and provided biological samples for HIV and STI testing. Those who completed study procedures were compensated between $\$ 35$ and $\$ 50$ for their time and between $\$ 15$ and $\$ 25$ if they recruited an eligible 


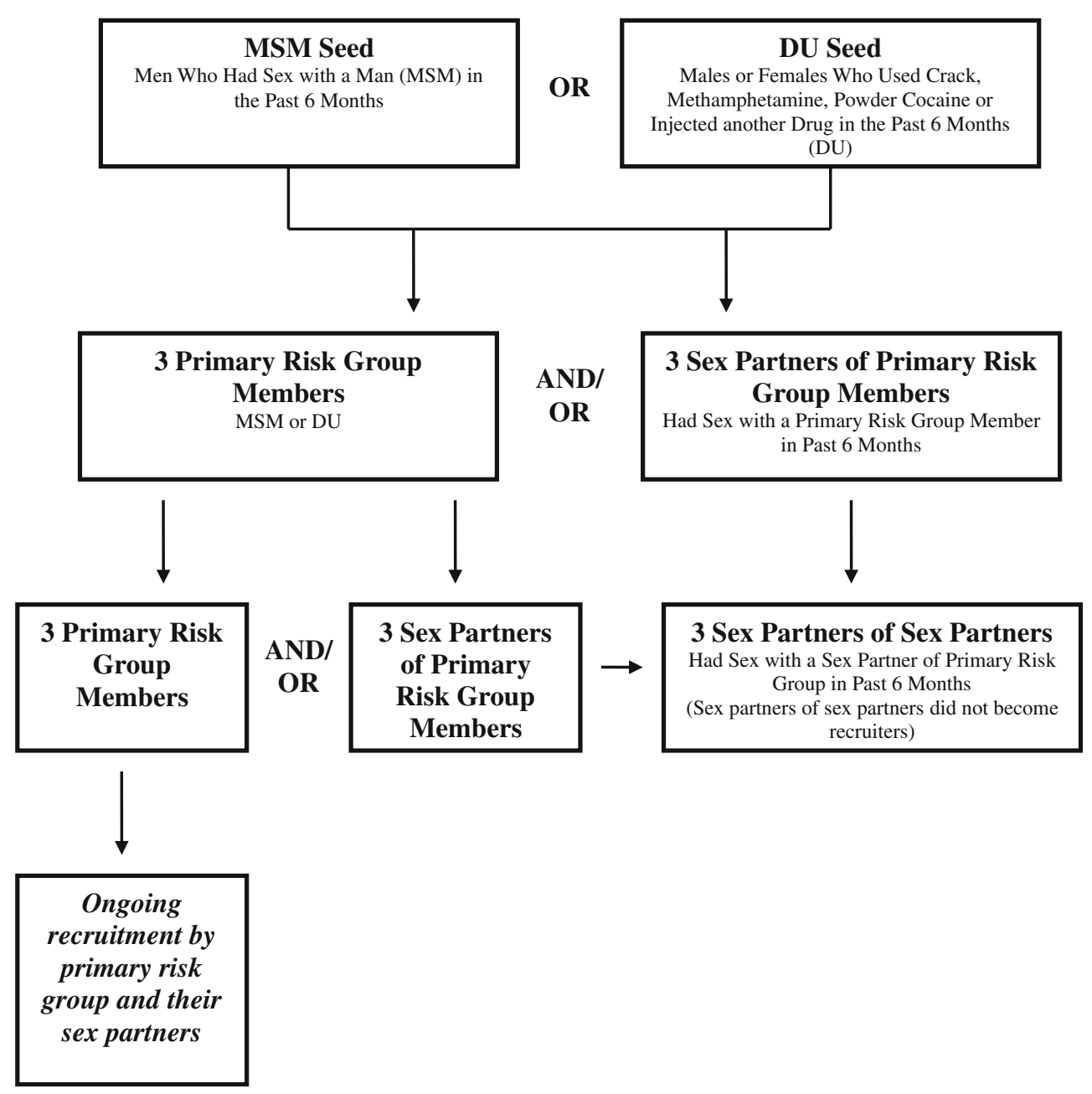

Fig. 1 Original SATHCAP recruitment design

participant. Wave 1 respondents could not participate in Wave 2. No follow-up interviews were conducted. (See Iguchi et al. [54] for a detailed description of SATHCAP study procedures.)

\section{Measures}

The ACASI asked about demographics, health and health behavior, HIV risks such as drug and alcohol use, types of sexual partnerships, and other risk behaviors. Drug use and sexual risk questions were asked about global (typical) and event-level (specific) behaviors. Global questions asked if they had ever engaged in certain behaviors, for example, "have you ever used crack" and, if so, "how many days in the past 30 have you used crack," and so on. Event-level questions asked about specific behaviors in which they engaged during their last sexual contact with each of the sexual partners whose initials they provided at the start of the event-level questions. Event-level questions asked questions such as, "the last time you had sex with (partner with initials 'AA'), did you use crack/methamphetamine/ etc." These questions were asked about their last sexual acts with up to five partners. Respondents first were asked about their last three partners. If their last three partners were not also an injecting partner or main partner, they were then asked about behaviors with any injecting and main partners.

The dependent variable was defined as having protected vaginal sex (i.e., used a condom throughout the whole sexual episode) during the last sexual event with any of up to five sexual partners. The unit of analysis was the specific sexual event. Individual-level contextual predictors included: (1) race/ethnicity; (2) homelessness; (3) woman's HIV status; and (4) woman's use of crack, methamphetamine or heroin in the 30 days preceding the interview. Event-level partner risk perception variables included: (1) partner HIV status; (2) partner bisexuality; (3) partner concurrency (i.e., perception of a partner having other partners at the same time); and (4) whether the partner had ever injected drugs. Event-level contextual predictor variables included: (1) 
partner race; (2) partner type (not a main partner vs. main partner); (3) exchange of sex for money or drugs; (4) woman's use of alcohol, crack, powder cocaine, methamphetamine or heroin during the sexual episode; and (5) partner's use of alcohol, crack, powder cocaine, methamphetamine or heroin during the sexual episode.

\section{Statistical Analysis}

We analyzed the data in three stages. First, we modeled univariate logistic random effects to examine the relationship between each of the four perception variables and condom use, without controlling for contextual variables. Next we fit models for each perception variable that contained demographics variables (e.g., respondent race and partner race) and each contextual variable to determine the specific effects of each contextual variable and the relationship between the perception variables and condom use, first testing the contextual variables individually (to determine which, if any, affected the relationship between risk perceptions and condom use) and then together. Finally, we fit one logistic regression random effects model that contained only the variables from the previous models which significantly increased or decreased the odds of condom use at the 0.05 level. We forced into each model a site variable and a coupon type variable to control for study city (Los Angeles, Raleigh-Durham, and Chicago) and for the way in which the woman was recruited-as a seed, a drug user, or as a sex partner. We conducted Wald tests to test the fit with those variables having more than two categories in each model. We also tested for interactions between each perception variable and each contextual variable. Given the large number of interactions we tested (44) and the expectancy that two interactions would be significant at the $p=0.05$ level by chance alone, we did not include interactions in the final model unless they were significant at the 0.01 level.

To properly accommodate the multiple observations (i.e., sex partners) from a single respondent, all models were multi-level random effects logistic regression models (STATA version 10.0, xtlogit, random effects) [55]. Random effects models can estimate effects for both individual-level and event-level covariates [55].

Of the original 1,967 women respondents, 135 did not report any vaginal sex with a recent sexual partner and were omitted from the analysis. An additional 165 were excluded because they had data missing at random for at least one partner (i.e., events with missing data were not associated with specific demographic characteristics or outcomes) for one or more variables due to errors in skip patterns or other errors. Only a small percentage $(2 \%)$ of respondents had missing responses due to refusing to answer a question. These also were excluded.

\section{Results}

Demographics and Individual-Level Risk Characteristics

Women who participated in the study were between 18 and 73 years of age, with a mean age of 41 (median and mode $=42$ ), and were predominantly African American $(74 \%)$ and were poor (Table 1$)$. The majority (70\%) earned less than $\$ 500$ per month and reported having no health insurance $(60 \%)$. Five percent $(n=89)$ reported being HIV positive and $40 \%$ reported not being aware of their HIV status.

Most women (93\%) reported vaginal sex in the past 6 months and of these, $67 \%$ reported unprotected vaginal sex for at least one episode. Seventy-three percent were drug users; half reported crack cocaine use in the past 30 days and almost a third reported heroin use. The majority $(72 \%)$ reported getting drunk on at least one day out of the past 30 days.

\section{Partner and Event-Level Risk Characteristics}

Women generally believed partners were not bisexual (67\%) and that partners did not inject drugs (73\%); however, many women were not aware of their partners' HIV status $(56 \%)$ (Table 2). Almost half (49\%) believed that their sexual partners had had concurrent partners. In $43 \%$ of episodes, women had exchanged sex for money or drugs. In about one-third, women reported that they (33\%) and/or their partners $(31 \%)$ used crack. Women and their partners used methamphetamine during a very small percentage of events (2\% each), while in $28 \%$ and $25 \%$ of events women and partners, respectively, had used heroin.

\section{Univariate Associations between Partner Risk \\ Perception Variables and Condom Use}

In univariate models, women who perceived that their partners had concurrent partners were more likely to have used a condom during a sexual event (Table 3 ). In addition, a woman's ignorance of her partner's risk status (i.e., she indicated she did not know if her partner had HIV, had concurrent partners, had engaged in bisexual behavior, or was a drug injector) was associated with significantly higher odds of condom use.

Multivariate Models: Adjusted Effects of Partner Risk Perception Variables on Condom Use

Although results varied slightly for each partner risk perception model, in general adding partner type (not a main partner v. main partner) and/or woman's HIV status (HIV 
Table 1 Demographics and individual-level risk characteristics $(n=1,967)^{\mathrm{a}}$

\begin{tabular}{|c|c|c|}
\hline & $\%^{\mathrm{b}}$ & $n$ \\
\hline \multicolumn{3}{|l|}{ Age } \\
\hline \multicolumn{3}{|l|}{ Mean: 41.34 (SD 9.74); Range: 18-73 } \\
\hline $18-29$ & 15 & 298 \\
\hline $30-39$ & 25 & 487 \\
\hline $40-49$ & 42 & 818 \\
\hline $50-59$ & 17 & 335 \\
\hline$>59$ & 1 & 26 \\
\hline Missing & 0.2 & 3 \\
\hline \multicolumn{3}{|l|}{ Race } \\
\hline African American & 74 & 1,449 \\
\hline Caucasian & 16 & 305 \\
\hline Hispanic & 9 & 173 \\
\hline Other race & 2 & 40 \\
\hline \multicolumn{3}{|l|}{ Self-reported HIV status } \\
\hline HIV negative & 51 & 1,002 \\
\hline HIV positive & 5 & 89 \\
\hline Do not know HIV status & 40 & 777 \\
\hline Missing & 5 & 99 \\
\hline \multicolumn{3}{|l|}{ Income per month } \\
\hline $0-\$ 500$ & 70 & 1,375 \\
\hline$\$ 501-\$ 1,000$ & 19 & 366 \\
\hline More than $\$ 1,000$ & 11 & 213 \\
\hline Missing & 0.6 & 13 \\
\hline Homeless in the past year & 41 & 810 \\
\hline No health insurance & 60 & 1,178 \\
\hline $\begin{array}{l}\text { Had any unprotected vaginal sex with any male } \\
\text { partner in the last } 6 \text { months }\end{array}$ & 67 & 1,832 \\
\hline Used crack cocaine in the past 30 days & 52 & 1,032 \\
\hline Used heroin in the past 30 days & 30 & 585 \\
\hline Used methamphetamine in the past 30 days & 5 & 103 \\
\hline Used powder cocaine in the past 30 days & 22 & 442 \\
\hline Got drunk at least one day in the past 30 days & 72 & 1,416 \\
\hline
\end{tabular}

a Table includes all women in the sample; women who did not have vaginal sex were removed later during analysis

b May not sum to $100 \%$ due to rounding

negative, HIV positive, and don't know) to each model diminished the effects of the perception variables on condom use before any other contextual factors were added, with the exception of perceptions of perceived partner injection drug use (Table 4). Specifically, when both partner type and woman's HIV status were added to the partner HIV status and partner bisexuality models, the perception variables (i.e., not knowing a partner's HIV status and not knowing if a partner was bisexual) no longer were significant predictors of condom use. When we added partner type alone to the perceived partner concurrency partner model, neither perceived concurrency nor lack of
Table 2 Partner and event-level risk episode characteristics $(n=4,088)^{\mathrm{a}}$

\section{$\%^{\mathrm{b}} \quad n$}

Perception of partner HIV status

Partner is HIV negative

$39 \quad 1,611$

Partner is HIV positive

89

Do not know partner HIV status

Missing

2,297

Perception of partner bisexuality

Partner is not bisexual

91

Partner is bisexual

2,753

Do not know if partner is bisexual

484

Missing

$19 \quad 778$

Perception of partner concurrency

Partner does not have concurrent partners $\quad 31 \quad 1,282$

Partner has concurrent partners

$49 \quad 2,018$

Do not know if partner has concurrent partners $\quad 19 \quad 778$

Missing

$0.2 \quad 10$

Perception of partner injection drug use

Partner does not inject drugs

3,002

Partner injects drugs

Do not know if partner injects drugs

Missing

$20 \quad 818$

Partner type

$\begin{array}{lll}\text { Not a main partner } & 57 & 2,320\end{array}$

$\begin{array}{lll}\text { Main partner } & 42 & 1,707\end{array}$

Missing $\quad 1 \quad 61$

$\begin{array}{lll}\text { Woman exchanged sex for money or drugs } & 43 & 1,764\end{array}$

Woman used crack cocaine during sexual event $\quad 33 \quad 1,361$

$\begin{array}{lll}\text { Partner used crack cocaine during sexual event } \quad 31 & 1,258\end{array}$

$\begin{array}{lll}\text { Woman used methamphetamine during sexual event } & 2 & 71\end{array}$

Partner used methamphetamine during sexual event $\quad 2 \quad 83$

$\begin{array}{lll}\text { Woman used heroin during sexual event } & 28 & 1,149\end{array}$

$\begin{array}{lll}\text { Partner used heroin during sexual event } & 25 & 1,014\end{array}$

${ }^{\mathrm{a}} n$ is higher than the number of respondents due to respondents reporting on multiple sexual episodes ( $n=\#$ of events)

b May not sum to $100 \%$ due to rounding

awareness of concurrency significantly predicted condom use. Adding contextual variables to the perceived injection drug use model did not change the significance of the effect of not knowing a partner's injection history; however, the Wald test was no longer significant (data not shown), indicating the ultimate non-significance of the variable in the multivariate model.

Final Multivariate Models: Associations of Contextual Variables and Condom Use

Contextual factors associated (additively) with decreased odds of condom use were having sex with a main partner, 
Table 3 Univariate random intercept logistic regression models
${ }^{\text {a }} n$ is lower than total number of events due to missing data

b Wald test: $p<0.01$

${ }^{c} p<0.01$

Table 4 Multivariate random intercept logistic regression models: adjusted effects of perception variables after adding partner type and woman's HIV status
${ }^{\text {a }} n$ is lower than total number of events due to missing data

${ }^{\mathrm{b}} p<0.01$

c Wald test: $p<0.01$

${ }^{\mathrm{d}} p<0.05$

\begin{tabular}{|c|c|c|}
\hline & \multicolumn{2}{|c|}{$\begin{array}{l}\text { Protected vaginal sex ( } n=1,667 \text { individuals, } \\
\left.3,022^{\mathrm{a}} \text { events }\right)\end{array}$} \\
\hline & OR & $95 \% \mathrm{CI}$ \\
\hline \multicolumn{3}{|l|}{ Partner HIV status ${ }^{\mathrm{b}}($ ref $=$ negative $)$} \\
\hline Partner is HIV positive & 2.01 & $0.92-4.37$ \\
\hline Do not know partner HIV status & $1.69^{\mathrm{c}}$ & $1.30-2.20$ \\
\hline \multicolumn{3}{|l|}{ Partner bisexuality ${ }^{\mathrm{b}}$ (ref $=$ not bisexual) } \\
\hline Partner is Bisexual & 1.04 & $0.70-1.55$ \\
\hline Do not know if partner is bisexual & $1.99^{\mathrm{c}}$ & $1.43-2.76$ \\
\hline \multicolumn{3}{|l|}{ Partner concurrency ${ }^{\mathrm{b}}$} \\
\hline Partner Has Concurrent Partners & $1.42^{\mathrm{c}}$ & $1.09-1.87$ \\
\hline Do not know if partner has concurrent partners & $2.47^{\mathrm{c}}$ & $1.70-3.57$ \\
\hline \multicolumn{3}{|l|}{ Partner injection drug use ${ }^{\mathrm{b}}$ (ref $=$ no history) } \\
\hline Partner has injected & 0.94 & $0.69-1.29$ \\
\hline Do not know if partner has injected & $1.98^{\mathrm{c}}$ & $1.13-3.47$ \\
\hline
\end{tabular}

the woman being homeless in the past year, the woman's alcohol use during the sexual episode, and the woman's use of crack in the past 30 days, holding constant all other factors (Table 5). The only contextual factor associated with increased odds of condom use was the woman's HIV positive status. Contextual factors not associated with increased or decreased odds of condom use were the woman's race or her partner's race, exchange of sex for money or drugs, the woman's use of methamphetamine in the past 30 days, the woman's or her partner's use of crack or methamphetamine during a sexual episode, and the partners' use of alcohol during the sexual episode. 


\section{Discussion}

Paradoxically, perceptions among low-income mostly African-American women that their sexual partners engage in high risk behaviors, such as having male partners, having concurrent partners, or injecting drugs, or that a partner is HIV positive, or lack of awareness of these partner risk factors, do not seem to be associated with condom use, particularly when certain contextual factors are taken into account. About half of the women believed their partners had partners at the same time as they were partners with them (partner concurrency), but perceptions of partner concurrency were associated with condom use only before type of partner (not a main partner v. a main partner) was taken into account. After partner type was added to the model, a perception of concurrency was no longer associated with condom use and, consistent with prior studies, sex with a main partner was associated with greatly decreased odds of using a condom. This finding not only reports higher rates of perceived and actual concurrency than those previously reported $[7,8,56](49 \%$ of all women perceived that partners had other partners and of all women who had unprotected sex with a main partner, $42 \%$ believed their partners also had other partners), but also suggests that women are not likely to use condoms with main partners despite perceiving that their partners have other partners.

For the other three perceptions of partner risk, a perception that a partner was high risk (i.e., they were HIV positive, bisexual, or injected drugs) was not associated with condom use. Not knowing a partner's risk status initially was associated with condom use, but not after partner type and the woman's HIV status were taken into account. The association between lack of awareness of a partner's risk factors and condom use prior to consideration of partner type may be a proxy for lack of familiarity or closeness with the partner. When partner type and the woman's HIV status were included, lack of awareness of a partner's risk factors no longer was associated with condom use. The lack of association between women's perceptions of their partners' risk factors and condom use indicates that HIV prevention interventions must extend beyond disclosure of partner risk factors and take into account the dynamics that accompany sex with a main or close partner.

Although the finding that women are less likely to use condoms with their main partners is not new or surprising $[5,11,57]$, our finding that this behavior persists despite perceptions that partners may be at high risk for HIV transmission emphasizes the urgent need for interventions to be more effective for women (and men) with their main partners. Although theory-based interventions have proven effective at increasing condom use among women [57-60], they are not typically effective at changing condom use behaviors between women and their main partners [57, 61]. Because reasons for lack of condom use with main partners are varied, including gender- and culture-based power issues such as perceived and real partner disapproval of condom use $[14,62]$ possibly related to a fear of violence [10] and loss of financial support [15], lack of cultural support for women (women of color in particular) initiating condom use, [62] and issues related to love, trust and intimacy between main partners [15, 61], interventions must not only take into account culture and gender-specific issues, but they also must remain flexible to dyad- and woman-specific factors that influence condom use and should also include interventions with couples. Despite our findings that suggest that perceptions of a partner's risk factors do not affect condom use, it should be noted that interventions with heterosexual couples [63-69] - serodiscordant couples in particular [63, 64, 67-69]-have been effective at increasing condom use in couples. In Africa, counseling and testing interventions with couples have long been associated with increased condom use and reduced seroconversion rates [63, 67-69]. In the United States, recent findings from Project Eban, a randomized controlled behavioral intervention for African American serodiscordant couples, suggest that a couples intervention can reduce HIV risk behaviors [64]. Additional randomized controlled trials are needed to test relationship interventions with couples in which both partners are HIV negative but may exhibit other risk factors, such as having concurrent partners, and with very low-income couples who may be involved with drugs and have less stable relationships.

Additional contextual variables associated with decreased odds of condom use in this study were homelessness, crack use, and alcohol use. These findings, consistent with prior research $[5,11,25,28,30,33,37,70]$, suggest that these factors interfere with condom use by at-risk women. That homeless women are less likely to use condoms suggests that poor and homeless women typically face more immediate concerns than the long-term risk of HIV, such as, among other things, finding shelter for the night and feeding their children [25, 30]. Crack and alcohol use may reduce condom use due to their disinhibiting effect on risk behaviors $[33,70]$ and may also be associated with the exchange of sex for money or drugs [71, 72]. Although interventions exist that take into account key factors, such as crack use, that erode efficacy of traditional HIV prevention approaches in promoting condom use [58,59], effects of such interventions may not endure over time and may require ongoing booster sessions to reinforce them [73].

On a slightly more hopeful and personally responsible note, women who are aware that they are HIV positive are over four times as likely to use a condom than women who believe they are HIV negative, suggesting that women's 
Table 5 Final multivariate random intercept logistic regression model: contextual factors associated with condom use

a $n$ is lower than total number of events due to missing data

${ }^{\mathrm{b}} p<0.01$

c Wald test: $p<0.01$

${ }^{\mathrm{d}} p<0.05$
Protected vaginal sex ( $n=1,667$ individuals, $3,022^{\mathrm{a}}$ events)

AOR $95 \% \mathrm{CI}$

awareness of their own risk factors may be effective in reducing risk for HIV transmission from themselves to others. However, the results for the comparison group (women who believe they are HIV negative) and for women who do not know their HIV status are more concerning and suggest ongoing vulnerability for at-risk women of contracting HIV. Women who think they are HIV negative are much less likely to use condoms than HIV positive women (AOR 0.27, 95\% CI 0.12-0.59). This finding, along with the higher likelihood that women who are not aware of their own HIV status will engage in unprotected sex and the high percentage of women who were not aware of their own HIV status (40\%), suggests that much greater efforts must be made to deliver HIV testing and more effective prevention interventions to atrisk women. Although studies consistently recommend more HIV testing and greater access to interventions for atrisk women, outside of specifically funded projects, widespread implementation of testing and effective interventions is not yet a reality [74-78]. For example, although there is evidence for the feasibility and effectiveness of interventions such as rapid HIV testing in medical [79-81], criminal justice [82, 83], and drug treatment [82, 84] settings as well as community-based organizations such as homeless shelters and public parks [85], studies suggest that dissemination and implementation of rapid testing in these settings is lagging behind the evidence due to restrictive state policies, and administrative, organizational, and funding barriers [74, 76, 77]. Although it is clear that effective interventions exist, more emphasis must be placed diffusing these interventions in order to reach women who are at the greatest risk for HIV.

Our findings about the relative unimportance of perceptions of partner risk behaviors and health risks in condom use among these women, the risk of HIV transmission to women from their main partners, and the ongoing HIV risk for the large number of HIV negative women and women who do not know their HIV status, emphasize the need for interventions that are relevant to the context of the lives of very low-income, drug-using women and the need to expand the reach of these interventions [57, 60, 62, 86]. Our findings confirm that HIV is still a risk for low-income women in urban areas, particularly those who are homeless and those who use crack and alcohol. We suggest that further action include two key elements: (1) adaptation of existing culturally congruent, relationship-based HIV prevention interventions $[64,65]$ to address the realities of very low-income, substance-using African American women and their main partners, such as less-stable relationships and partners who may not be amenable to attending a couples intervention; and (2) policy-based, funding, and organizational strategies for expanding diffusion of rapid HIV testing into medical, criminal justice, and other community-based settings.

\section{Limitations}

First, the sample is not representative of all low-income women and must be treated as a convenience sample with limitations on the generalization of results. The sample also was composed predominantly of drug-using women, thus limiting comparison to behaviors among non-drug using women. In addition, the study did not measure all contextual variables that might influence condom use. For example, we did not measure women's acceptance of condoms as protective for HIV, their self-efficacy for negotiating and using condoms, women's perceptions of their own power in relation to their partners, and whether or not the women were aware that partner factors, such as concurrency and bisexuality, were risky. Limitations notwithstanding, the study measured event-level sexual behaviors in a sample of women at high risk for HIV due to their low-income status (i.e., lack of access to prevention 
and treatment resources), their substance use and abuse, and their association with high-risk men. Findings may also have important prevention implications for older (the mean age was 42), low-income women, especially drug-using women in urban areas.

Acknowledgments Analysis and reporting supported by UCLA AIDS Institute. SATHCAP study supported through NIDA Grants U01DA017373, U01DA017377, U01DA017378, U01DA017387, and U01DA017394.

Open Access This article is distributed under the terms of the Creative Commons Attribution Noncommercial License which permits any noncommercial use, distribution, and reproduction in any medium, provided the original author(s) and source are credited.

\section{References}

1. CDC. HIV/AIDS among women fact sheet. 2007 [updated 2007]. http://www.cdc.gov/hiv/topics/women/resources/factsheets/pdf/ women.pdf. Accessed 11 April 2010.

2. Hader S, Smith D, Moore J, Holmberg S. HIV infection in women in the United States: status at the millennium. JAMA. 2001;285(9):1186-92.

3. CDC. HIV/AIDS surveillance report, 2005. vol 17. Rev ed. Atlanta: U.S. Department of Health and Human Services; 2007.

4. Catania J, Coates TJ, Stall R, et al. Prevalence of AIDS-related risk factors and condom use in the United States. Science. 1992;258(5085):1101-6.

5. Misovich DJ, Fisher JD, Fisher WA. Close relationships and elevated HIV risk behavior: Evidence and possible underlying psychological processes. Rev Gen Psychol. 1997;1(1):72-107.

6. Witte SS, El-Bassel N, Gilbert L, Wu E, Chang M. Lack of awareness of partner STD risk among heterosexual couples. Perspect Sex Reprod Health. 2010;42(1):49-55.

7. Drumright LN, Gorbach PM, Holmes KK. Do people really know their sex partners? Concurrency, knowledge of partner behavior, and sexually transmitted infections within partnerships. Sex Transm Dis. 2004;31(7):437-42.

8. Riehman KS, Wechsberg WM, Francis SA, Moore M, MorganLopez A. Discordance in monogamy beliefs, sexual concurrency, and condom use among young adult substance-involved couples: implications for risk of sexually transmitted infections. Sex Transm Dis. 2006;33(11):677-82.

9. Corbett AM, Julia D-G, Helena H, Margaret RW. A little thing called love: condom use in high-risk primary heterosexual relationships. Perspect Sex Reprod Health. 2009;41(4):218-24.

10. Amaro H. Love, sex and power: considering women's realities in HIV prevention. Am Psychol. 1995;50(6):437-47.

11. Dolcini MM, Catania JA, Coates TJ, et al. Demographic characteristics of heterosexuals with multiple partners: the mational AIDS behavioral surveys. Fam Plann Perspect. 1993;25(5): 208-14.

12. Thorburn S, Harvey SM, Ryan EA. HIV prevention heuristics and condom use among African-Americans at risk for HIV. AIDS Care. 2005; 17(3):335-44.

13. Witte SS, El-Bassel N, Gilbert L, Wu E, Chang M, Steinglass P. Recruitment of minority women and their main sexual partners in an HIV/STI prevention trial. J Womens Health. 2004;13(10): 1137-47.

14. St. Lawrence JS, Eldridge GD, Reitman D, Little CE, Shelby MC, Brasfield TL. Factors influencing condom use among African
American women: implications for risk reduction interventions. Am J Community Psychol. 1998;26(1):7-28.

15. Pivnick A. HIV infection and the meaning of condoms. Cult Med Psychiatry. 1993;17(4):431-53.

16. The NIMH Multisite HIV/STD Prevention Trial for African American Couples Group. Risky sexual behavior and correlates of STD prevalence among African American HIV serodiscordant couples. AIDS Behav. 2010;14(5):1023-31.

17. The NIMH Multisite HIV/STD Prevention Trial for African American Couples Group. The contribution of male and female partners' substance use to sexual risks and STDs among African American HIV serodiscordant couples. AIDS Behav. 2010;14(5): 1045-54.

18. Adimora AA, Schoenbach VJ. Contextual factors and the blackwhite disparity in heterosexual HIV transmission. Epidemiology. 2002;13(6):707-12.

19. Morris M, Kretzschmar M. Concurrent partnerships and the spread of HIV. AIDS. 1997;11(5):641-8.

20. Stokes JP, McKirnan DJ, Doll L, Burzette R. Female partners of bisexual men: what they don't know might hurt them. Psychol Women Q. 1996;20(2):267-84.

21. Espinoza L, Hall HI, Hardnett F, Selik RM, Ling Q, Lee LM. Characteristics of persons with heterosexually acquired HIV infection, United States 1999-2004. Am J Public Health. 2007; 97(1):144-9.

22. Azjen I, Fisbein M. Understanding attitudes and predicting social behavior. Englewood Cliffs, NJ: Prentice Hall; 1980.

23. Janz NK, Becker MH. The health belief model: a decade later. Health Educ Q. 1984;11(1):1-47.

24. Kowaleski M, Henson K, Longshore D. Rethinking perceived risk and health behavior: a critical review of HIV prevention research. Health Educ Behav. 1997;24(3):313-25.

25. Mays V, Cochran S. Issues in the perception of AIDS risk and risk reduction activities by Black and Hispanic/Latina women. Am Psychol. 1998;43(11):949-57.

26. Wingood GM, DiClemente RH. Application of the theory of gender and power to examine HIV-related exposures, risk factors, and effective interventions for women. Health Educ Behav. 2000;27(5):539-65.

27. Laurencin CT, Christensen DM, Taylor ED. HIV/AIDS and the African-American community: a state of emergency. Journal Natnl Med Assoc. 2008;100(1):35-43.

28. Ickovics JR, Beren SE, Grigorenko EL, Morrill AC, Druley JA, Rodin J. Pathways of risk: race, social class, stress, and coping as factors predicting heterosexual risk behaviors for HIV among women. AIDS Behav. 2002;6(4):339-50.

29. Logan T, Cole J, Leukefeld C. Women, sex, and HIV: social and contextual factors, meta-analysis of published interventions, and implications for practice and research. Psychol Bull. 2002; 128(6):851-85.

30. Wenzel SL, Tucker JS, Elliott MN, Hambarsoomians K. Sexual risk among impoverished women: understanding the role of housing status. AIDS Behav. 2007;11(6 Suppl):9-20.

31. Robles RR, Matos TD, Colon HM, Marrero CA, Reyes JC. Effects of HIV testing and counseling on reducing HIV risk behavior among two ethnic groups. Drugs Soc. 1996;9(1-2):173-84.

32. Semaan S, Des Jarlais DC, Malow R. Behavior change and health-related interventions for heterosexual risk reduction among drug users. Subst Use Misuse. 2006;41(10-12):1349-78.

33. Leigh BC, Stall R. Substance use and risky sexual behavior for exposure to HIV: issues in methodology, interpretation, and prevention. Amer Psychol. 1993;48(10):1035-45.

34. Miller M, Liao Y, Wagner M, Korves C. HIV, the clustering of sexually transmitted infections, and sex risk among African American women who use drugs. Sex Transm Dis. 2008;35(7): 696-702. 
35. Elifson KW, Klein H, Sterk CE. Drug problems and "at risk" women's involvement in HIV risk behaviors. Sozial und Praventive Medizine. 2004;49(3):198-207.

36. Wang MQ, Collins CB, Kohler CL, DiClemente RJ, Wingood G. Drug use and HIV risk-related sex behaviors: a street outreach study of black adults. South Med J. 2000;93(2):186-90.

37. Wingood GM, DiClemente RJ. The influence of psychosocial factors, alcohol, drug use on African-American women's highrisk sexual behavior. Am J Prev Med. 1998;15(1):54-9.

38. Timpson SC, Williams ML, Bowen AM, Keel KB. Condom use behaviors in HIV-infected African American crack cocaine users. Subst Abus. 2003;24(4):211-20.

39. Hwang LY, Ross MW, Zack C, Bull L, Rickman K, Holleman M. Prevalence of sexually transmitted infections and associated risk factors among populations of drug abusers. Clin Infect Dis. 2000;31(4):920-6.

40. Gorbach P, Holmes K. Transmission of STIs/HIV at the partnership level: beyond individual-level analyses. J Urban Health. 2003;80(4 Suppl 3):iii15-35.

41. Corbin WR, Fromme K. Alcohol use and serial monogamy as risks for sexually transmitted diseases in young adults. Health Psychol. 2002;21(3):229-36.

42. Schroder KE, Johnson CJ, Wiebe JS. An event-level analysis of condom use as a function of mood, alcohol use, and safer sex negotiations. Arch Sex Behav. 2007;38(2):283-9.

43. Bogart LM, Walt LC, Pavlovic JD, Ober AJ, Brown N, Kalichman SC. Cognitive strategies affecting recall of sexual behavior among high-risk men and women. Health Psychol. 2007;26(6): 787-93.

44. Perrino T, Fernandez MI, Bowen GS, Arheart K. Main partner's resistance to condoms and HIV protection among disadvantaged, minority women. Women Health. 2005;42(3):37-56.

45. Simoni JM, Walters KL, Nero DK. Safer sex among HIV positive women: the role of relationships. Sex Roles. 2000;42(7/8): 692-707.

46. Janz N, Champion J, Strecher V. The health belief model. In: Glanz K, Rimer B, Marcus Lewis F, editors. Health behavior and health education: theory, practice, research. San Francisco: Jossey-Bass; 2002.

47. Abdul-Quader AS, Heckathorn DD, McKnight C, et al. Effectiveness of respondent-driven sampling for recruiting drug users in New York City: findings from a pilot study. J Urban Health. 2006;83(3):459-76.

48. Frost SD, Brouwer KC, Firestone Cruz MA, et al. Respondentdriven sampling of injection drug users in two U.S.-Mexico border cities: recruitment dynamics and impact on estimates of HIV and syphilis prevalence. J Urban Health. 2006;83(6):83-97.

49. Heckathorn D, Semaan S, Broadhead R, Hughes J. Extensions of respondent-driven sampling: a new approach to the study of injection drug users aged 18-25. AIDS Behav. 2002;6(1):55-67.

50. Ramirez-Valles J, Heckathorn DD, Vazquez R, Diaz RM, Campbell RT. From networks to populations: the development and application of respondent-driven sampling among IDUs and Latino gay men. AIDS Behav. 2005;9(4):387-402.

51. Robinson WT, Risser JM, McGoy S, et al. Recruiting injection drug users: a three-site comparison of results and experiences with respondent-driven and targeted sampling procedures. J Urban Health. 2006;83(6 Suppl):i29-38.

52. Stormer A, Tun W, Guli L, et al. An analysis of respondent driven sampling with injection drug users (IDU) in Albania and the Russian Federation. J Urban Health. 2006;83(6 Suppl):i73-82.

53. Wang J, Carlson R, Falck R, Siegal H, Rahmen A, Li L. Respondent-driven sampling to recruit MDMA users: a methodological assessment. Drug Alc Depend. 2005;78:147-57.

54. Iguchi M, Ober A, Berry S, Fain T, Heckathorn D. Simultaneous recruitment of drug users and men who have sex with men in the
United States and Russia using respondent driven sampling: sampling methods and implications. J Urban Health. 2009; 86(Suppl 1):5-31.

55. Rabe-Hesketh S, Skrondal A. Multilevel and longitudinal modeling using Stata. College Station: Stata Press; 2005.

56. Paik A. The contexts of sexual involvement and concurrent sexual partnerships. Perspect Sex Reprod Health. 2010;42(1): $33-42$.

57. St Lawrence JS, Wilson TE, Eldridge GD, Brasfield TL, O'Bannon RE 3rd. Community-based interventions to reduce low income, African American women's risk of sexually transmitted diseases: a randomized controlled trial of three theoretical models. Am J Community Psychol. 2001;29(6):937-64.

58. Wechsberg WM, Lam WK, Zule WA, Bobashev G. Efficacy of a woman-focused intervention to reduce HIV risk and increase selfsufficiency among African American crack abusers. Am J Public Health. 2004;94(7):1165-73.

59. Sterk CE, Theall KP, Elifson KW. Effectiveness of a risk reduction intervention among African American women who use crack cocaine. AIDS Educ Prev. 2003;15(1):15-32.

60. Wingood GM, DiClemente RJ. Enhancing adoption of evidencebased HIV interventions: promotion of a suite of HIV prevention interventions for African American women. AIDS Educ Prev. 2006;18(4):161-70.

61. O'Leary A. Women at risk for HIV from a primary partner: balancing risk and intimacy. Annu Rev Sex Res. 2000;11: 191-234.

62. Scott KD, Gilliam A, Braxton K. Culturally competent HIV prevention strategies for women of color in the United States. Health Care Women Int. 2005;26(1):17-45.

63. Allen S, Tice J, Van de Perre P, et al. Effect of serotesting with counselling on condom use and seroconversion among HIV discordant couples in Africa. BMJ. 1992;304(6842):1605-9.

64. El-Bassel N, Jemmott JB, Landis JR, et al. National Institute of Mental Health multisite Eban HIV/STD prevention intervention for African American HIV serodiscordant couples: a cluster randomized trial. Arch Intern Med. 2010;170(17):1594-601.

65. El-Bassel N, Witte SS, Gilbert L, et al. The efficacy of a relationship-based HIV/STD prevention program for heterosexual couples. Am J Public Health. 2003;93(6):963-9.

66. El-Bassel N, Witte SS, Gilbert L, et al. Long-term effects of an HIV/STI sexual risk reduction intervention for heterosexual couples. AIDS Behav. 2005;9(1):1-13.

67. Allen S, Serufilira A, Bogaerts J, et al. Confidential HIV testing and condom promotion in Africa. Impact on HIV and gonorrhea rates. JAMA. 1992;268(23):3338-43.

68. Kamenga M, Ryder RW, Jingu M, et al. Evidence of marked sexual behavior change associated with low HIV-1 seroconversion in 149 married couples with discordant HIV-1 serostatus: experience at an HIV counselling center in Zaire. AIDS. 1991;5(1):61-7.

69. Voluntary HIV-1 Counseling and Testing Efficacy Study Group. Efficacy of voluntary HIV-1 counselling and testing in individuals and couples in Kenya, Tanzania, and Trinidad: a randomised trial. The Voluntary HIV-1 Counseling and Testing Efficacy Study Group. Lancet. 2000;356(9224):103-12.

70. Morrison TC, DiClemente RJ, Wingood GM, Collins C. Frequency of alcohol use and its association with STD/HIV-related risk practices, attitudes and knowledge among an AfricanAmerican community-recruited sample. Int J STD AIDS. 1998;9(10):608-12.

71. Zule WA, Costenbader E, Coomes CM, et al. Stimulant use and sexual risk behaviors for HIV in rural North Carolina. J Rural Health. 2007;23(Suppl):73-8. Fall.

72. Wechsberg WM, Lam WK, Zule W, Hall G, Middlesteadt R, Edwards J. Violence, homelessness, and HIV risk among crack- 
using African-American women. Subst Use Misuse. 2003; 38(3-6):669-700.

73. Wechsberg WM, Novak SP, Zule WA, et al. Sustainability of intervention effects of an evidence-based HIV prevention intervention for African American women who smoke crack cocaine. Drug Alcohol Depend. 2010;109:205-12.

74. Bogart LM, Howerton D, Lange J, Becker K, Setodji CM, Asch SM. Scope of rapid HIV testing in urban U.S. hospitals. Public Health Rep. 2008;123(4):494-503.

75. St. Lawrence J, Fortenberry D. Behavioral Interventions for STDs: Theoretical Models and Intervention Methods. In: Aral S, Douglas J, Lipshutz J, editors. Behavioral interventions for prevention and control of sexually transmitted diseases. New York: Springer; 2007.

76. Bogart LM, Howerton D, Lange J, Becker K, Setodji CM, Asch SM. Scope of rapid HIV testing in private nonprofit urban community health settings in the United States. Am J Public Health. 2008;98(4):736-42.

77. Bogart LM, Howerton D, Lange J, et al. Provider-related barriers to rapid HIV testing in U.S. urban non-profit community clinics, community-based organizations (CBOs) and hospitals. AIDS Behav. 2008;14(3):697-707.

78. Rothman J, Rudnick D, Slifer M, Agins B, Heiner K, Birkhead G. Co-located substance use treatment and HIV prevention and primary care services, New York State, 1990-2002: a model for effective service delivery to a high-risk population. J Urban Health. 2007;84(2):226-42.
79. Knapp H, Anaya HD, Goetz MB. Attributes of an independently self-sustaining implementation: nurse-administered HIV rapid testing in VA primary care. Qual Manag Health Care. 2010; 19(4):292-7.

80. Anaya HD, Hoang T, Golden JF, et al. Improving HIV screening and receipt of results by nurse-initiated streamlined counseling and rapid testing. J Gen Intern Med. 2008;23(6):800-7.

81. Bardeguez AD, Denny T, Palumbo P, et al. Human immunodeficiency virus type 1 counseling and testing program in the prenatal setting. Infect Dis Obstet Gynecol. 1995;3(6):229-35.

82. Farabee D, Leukefeld CG. Opportunities for AIDS prevention in a rural state in criminal justice and drug treatment settings. Subst Use Misuse. 1999;34(4-5):617-31.

83. Beckwith CG, Atunah-Jay S, Cohen J, et al. Feasibility and acceptability of rapid HIV testing in jail. AIDS Patient Care STDS. 2007;21(1):41-7.

84. Gunn RA, Lee MA, Callahan DB, Gonzales P, Murray PJ, Margolis HS. Integrating hepatitis, STD, and HIV services into a drug rehabilitation program. Am J Prev Med. 2005;29(1):27-33.

85. Bowles KE, Clark HA, Tai E, et al. Implementing rapid HIV testing in outreach and community settings: results from an advancing HIV prevention demonstration project conducted in seven U.S. cities. Public Health Rep. 2008;123(Suppl 3):78-85.

86. Diallo DD, Moore TW, Ngalame PM, White LD, Herbst JH, Painter TM. Efficacy of a single-session HIV prevention intervention for black women: a group randomized controlled trial. AIDS Behav. 2010;14(3):518-29. 